\title{
Gastrointestinal Intervention
}

\author{
journal homepage: www. gi-intervention.org
}

Review Article

\section{Endoscopic resection for early gastric cancer: The current controversies}

\author{
Xian Feng Xia, Philip Wai Yan Chiu*
}

\section{A B S T R A C T}

Gastric cancer remained second commonest cancer worldwide. The diagnosis of early gastric cancer (EGC) is increasing in Japan and South Korea resulting in better oncological outcomes. Endoscopic resection (ER) is safe and effective treatment for EGC with minimal risk of lymph node metastasis. The oncological clearance of ER for EGC in expanded criteria remains controversial. Several retrospective studies showed that endoscopic submucosal dissection (ESD) achieved minimal local recurrence and excellent survival for EGC in expanded indications. With an increasing trend of cancer occuring in the aging population, ER will play a major role in treatment of EGC among elderly who usually have multiple comorbidities. Salvage gastrectomy is generally recommended for those with non-curative ESD, while further researches should be conducted to refine the risks of nodal metastasis for various submucosal EGCs. Endoscopic surveillance is recommended for long term follow-up of patients after curative ESD as the risk of metachronous cancer is significant. Eradication of Helicobacter pylori is generally recommended for EGC treated by ER with a view to reduce the risk of metachronous tumor.

Copyright (c) 2016, Society of Gastrointestinal Intervention. All rights reserved.

Keywords: Early gastric cancer; Endoscopic resection; Endoscopic submucosal dissection

\section{Introduction}

Early gastric cancer (EGC) is defined as carcinoma involving the mucosa and submucosa irrespective of lymph node status. The prevalence of EGC is up to 60\% in Japan and South Korea, mainly because of the nationwide gastric cancer screening program conducted for residents aged 40 years or above in both countries. Endoscopic resection (ER) has become the standard of treatment for intramucosal EGC with minimal risk of nodal metastasis, but there is a wide variation worldwide on application of ER for treatment of EGC.

ER appeared to be the preferred treatment for EGC compared with conventional radical gastrectomy as it is a curative intent minimally invasive treatment, and the stomach can be preserved (Table 1). ${ }^{1-5}$ Our previous case cohort study showed that patients receiving endoscopic submucosal dissection (ESD) for treatment of EGC could achieve a shorter median hospital stay and lower complication rate than those receiving gastrectomy. ${ }^{5}$ However, controversies abound upon certain aspects of ER for treatment of EGC. ${ }^{6}$ In this review, we will discuss the indications of ER for
EGC, and current concerns for the expanded indication, ER for elderly patients, and the need of surveillance for metachronous cancer.

\section{Absolute and Expanded Indication of Endoscopic Resection for Early Gastric Cancer}

Japanese Gastric Cancer Association had established guidelines for endoscopic management of EGC. ${ }^{7}$ Conventionally, only differentiated-type intramucosal cancer less than $2 \mathrm{~cm}$ in diameter with no ulceration is absolutely indicated for ER. In light of the histological analyses for large numbers of surgical specimens, patients meeting the absolute indication is predicted to have negligible risk of lymph node metastasis. ${ }^{8}$

However, clinical experiences demonstrated that some patients with intramucosal EGC larger than $2 \mathrm{~cm}$ showed no nodal metastasis. Resecting the stomach may become obsolete for these cases if the risk of nodal metastasis can be refined. By reviewing a large number of surgical cases who underwent gastrectomy for EGC, Gotoda et $\mathrm{al}^{9}$ clarified that the risk of lymph node metasta-

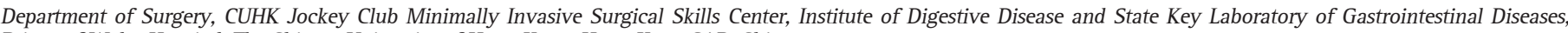
Prince of Wales Hospital, The Chinese University of Hong Kong, Hong Kong SAR, China

Received August 31, 2015; Revised October 11, 2015; Accepted October 19, 2015

* Corresponding author. Department of Surgery, Prince of Wales Hospital, 30-32, Ngan Shing Street, Shatin, N.T., Hong Kong SAR, China.

E-mail address: philipchiu@surgery.cuhk.edu.hk (P.W.Y. Chiu). 


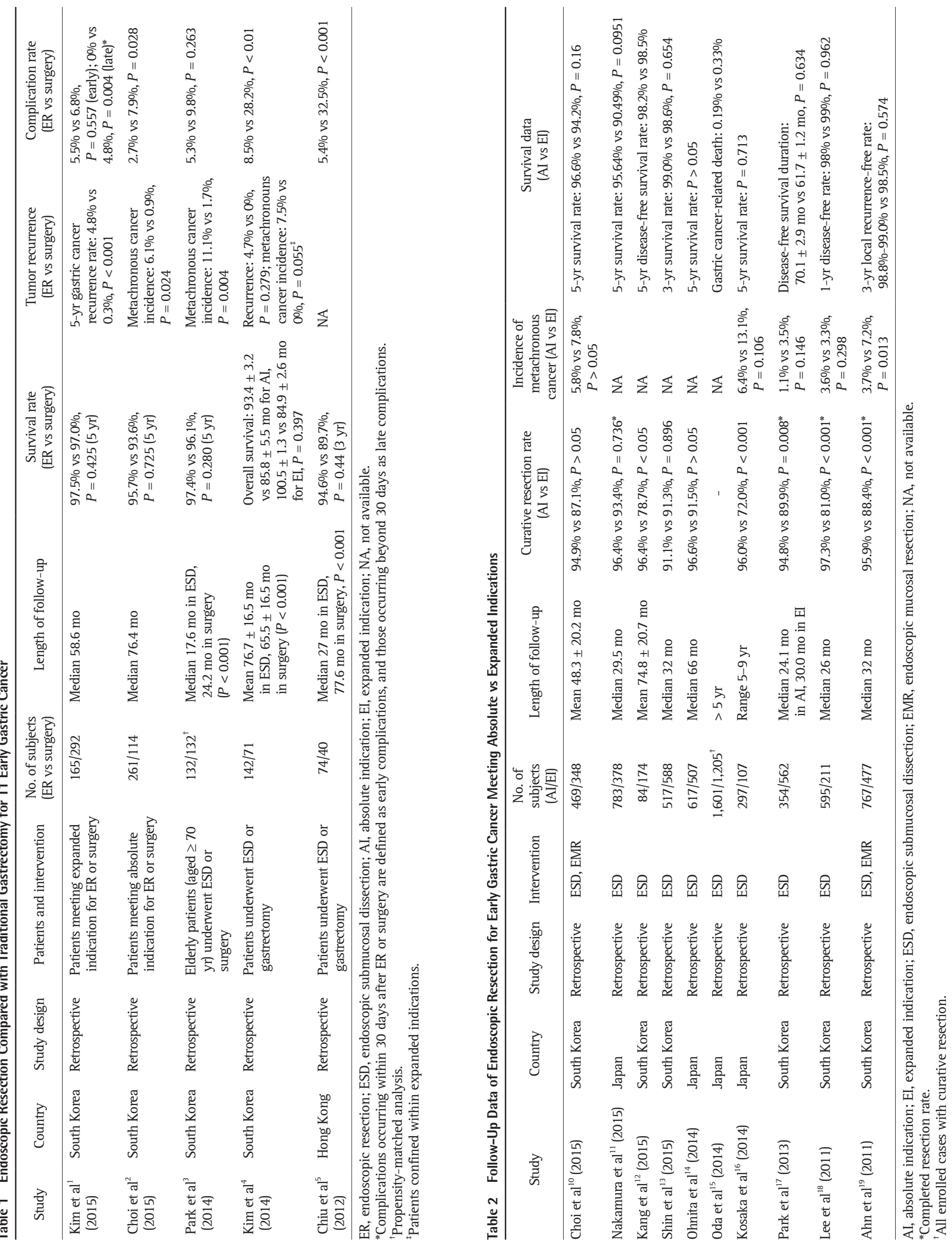


sis is minimal among four groups of EGC: (1) well-differentiated intramucosal cancers less than $30-\mathrm{mm}$ diameter without lymphovascular permeation regardless of ulceration; (2) well-differentiated intramucosal cancers without lymphovascular permeation and ulceration regardless of tumor size; (3) well-differentiated adenocarcinoma less than $30-\mathrm{mm}$ diameter with minute submucosal invasion (SM1, lesions invade into the submucosa less than 500 $\mu \mathrm{m})$ and without lymphovascular permeation; and (4) undifferentiated intramucosal lesions less than $20 \mathrm{~mm}$ in diameter without ulceration and lymphovascular permeation. Basing on these results, the indication of ER for EGC had expanded to include these categories.

\section{Evidence from Follow-up Data (Table 2) $)^{10-19}$}

To date, the validity of expanded indication for EGC remains controversial. One of the main concerns is the prediction of risk of lymph node metastasis for EGC in the expanded indication. Jee et $\mathrm{al}^{20}$ reviewed the 669 EGC patients who had surgical treatment. They found a rate of 2.3\% for lymph node metastasis in patients with mucosal cancer who met the expanded indication, and 4\% in patients with submucosal cancer who met the expanded indication. Meanwhile for 169 patients with well differentiated mucosal cancers without ulceration, no lymph node metastasis was found irrespective of lesion size. These data supported that well differentiated mucosal cancer of any size without ulceration can be considered as the expanded indication for ER. However, cautions should be paid for the other expanded indication since ER may carry a rate of $2.8 \%$ for lymph node metastasis in those patients.

Kim et $\mathrm{al}^{1}$ compared the outcomes of ER to surgery for treatment of EGC under the expanded indication. Although 5-year gastric cancer recurrence rate was higher for ER than for surgery (4.8\% vs $0.3 \%, P<0.001$ ), 5-year overall survival rate did not differ between the two groups $(97.5 \%$ for ER vs $97 \%$ for surgery, $P$ $=0.425$ ). Therefore, it concludes ER may be a potential alternative to surgery for EGC meeting the expanded indication. Long-term follow-up studies should be conducted to confirm the oncological clearance for ER of EGC under expanded criteria.

The clinical and oncological outcomes for EGCs treated by ER in expanded criteria were compared to those in the absolute indication. With a median follow-up period of 32 months, Ahn et $\mathrm{al}^{19}$ reported that EGC in absolute indication had a higher complete resection rate $(95.9 \%$ vs $88.4 \%, P<0.001)$ and a lower complication rate $(6.8 \%$ vs $9.8 \%, P=0.054)$ than those in extended indication. There was no difference in the local recurrence rate between the two groups of indication (0.9\% vs $1.1 \%, P=0.783$ ). In extended indication cases, 5-year survival rate (96.8\%) and 3-year disease-specific local recurrence-free rate (98.5\%) were clinically acceptable. Furthermore, ESD enabled a better en-bloc resection than endoscopic mucosal resection (EMR) in the extended indication group ( $91.1 \%$ vs $83.0 \%, P=0.006)$, suggesting that ESD would be a preferred method for treating these cancers (Fig. 1). ${ }^{16}$ Ohnita et $\mathrm{al}^{14}$ also reported a study including 1,209 EGC patients who had a median followed-up with 66 months after ESD procedure. The curative resection rate was $96.6 \%$ for absolute indication cases, and 91.5\% for expanded indication cases, without significant difference. The five-year survival rates showed no difference between the two groups.

Based on the current evidence with respect to clinical and oncologic outcomes, ESD is a feasible treatment for EGC in the expanded criteria. However, regular endoscopic surveillance should be warranted to detect the early cancer recurrence.

\section{Endoscopic Resection for the Undifferentiated Gastric Cancer Histology}

According to Japanese Gastric Cancer Treatment guidelines, undifferentiated EGC is recommended for ER only if there is no ulcer, intramucosal and less than $20 \mathrm{~mm}$ in size, as the risk of nodal metastasis is significant especially when the presence of lymphovascular permeation. ${ }^{17}$ Recently, there are reports showing enlightening results on ER for selected undifferentiated gastric cancers. $^{21,22}$ Oka et $\mathrm{al}^{23}$ retrospectively reviewed 84 patients with undifferentiated EGC. ESD was found to achieve a significantly higher complete resection rate than EMR (89\% vs 54\%, $P<0.01$ ). For those undifferentiated EGCs within the expanded indication for curative ER (non-ulcerative intramucosal and less than $20 \mathrm{~mm}$ in size without lymphovascular permeation), no local recurrence or distant metastasis was observed (follow-up with $93.6 \pm 38.4$ months). However, undifferentiated EGC meeting the criteria for non-curative resection had a significantly higher risk of lymph node and distant metastasis. Among the 19 cases of undifferentiated EGC of non-curative resection (follow-up with $108.3 \pm 38.7$ months), 3 patients died of metastatic carcinoma of stomach and 1 patient developed local recurrence with submucosal disease. While ESD may be acceptable for the treatment of undifferentiated EGC meeting the expanded criteria, caution should be exercised in careful selection of cases suitable for ER while radical gastrectomy should be offered to those found to have noncurative resection after ESD.
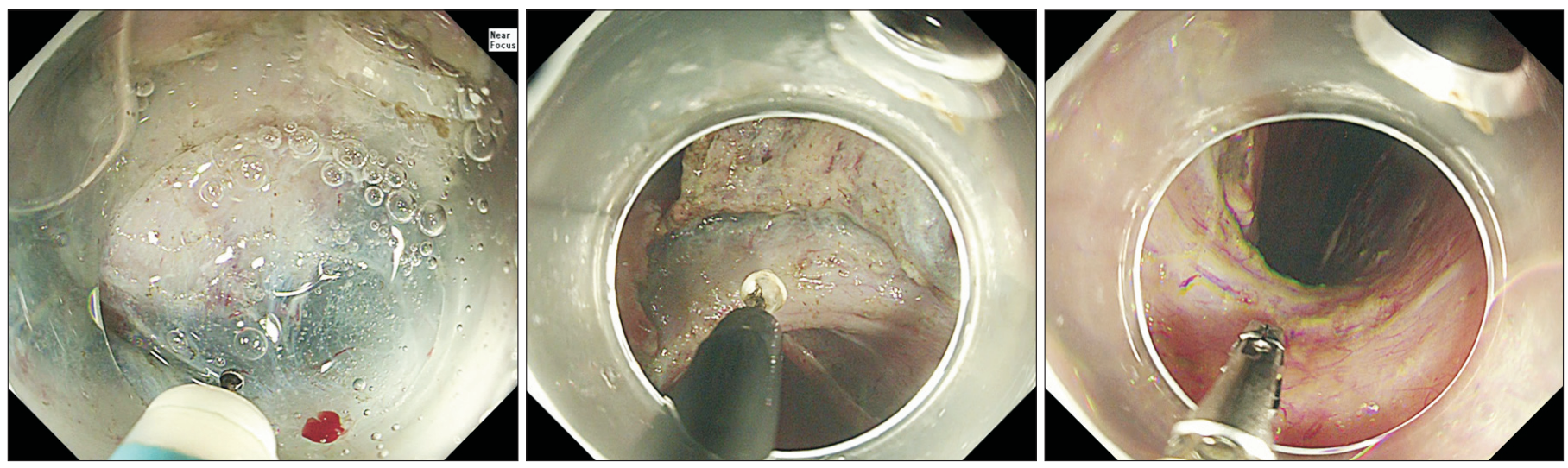

Fig. 1. Endoscopic submucosal dissection for treatment of early gastric cancer. 


\section{Endoscopic Resection in Elderly Patients with Early Gastric Cancer}

The safe practice of ESD required advanced endoscopic skills and appropriate training. ESD certainly carried higher risk of complications including bleeding and perforation than EMR. When compared to gastrectomy, ESD achieved better perioperative outcomes and quicker recovery as it does not involve gastrointestinal anastomosis and cutaneous incision. There will be significant advantages in treatment of EGC by ESD among elderly patients with multiple comorbidities, especially for those with comorbidities of heart and lung diseases. ${ }^{24}$ Park et $\mathrm{al}^{3}$ conducted a propensity-matched analysis including 518 EGC patients aged $>70$ years and compared clinical and oncologic outcomes of ESD to surgery. All the patients had EGC meeting expanded criteria for ER. The ESD group demonstrated a shorter hospital stay than gastrectomy, while the total adverse events did not differ. Those receiving ESD had a higher incidence of metachronous lesions detected during follow-up (11.1\% vs 1.7\%; 17.6-24.2 months). Although the 3-year adenoma- and cancer-free survival was superior in surgery compared with ESD treatment (96.3\% vs $80.0 \%$, $P<0.001$ ), the 5-year overall survival rate did not show significant difference $(96.1 \%$ vs $97.4 \%, P=0.280)$.

In general, salvage gastrectomy with standard lymph node dissection is recommended after non-curative ER for EGC to achieve curative surgical resection for non-curative ER beyond expanded criteria. ${ }^{14}$ However, the decision to salvage surgery is usually more complex for elderly patients who often had concomitant diseases and high risks for surgery. In 2011, Kusano et $\mathrm{al}^{25}$ reported the long-term survival data in an elderly patient ( $>75$ years old) cohort study. The overall and disease-free survival in patients under curative ER and those who had non-curative ER with salvage gastrectomy were the same. However, a significant difference in overall and disease-free survival was found between patients with curative ER and those who had non-curative ER without salvage gastrectomy (hazard ratio [HR] 1.89, 95\% confidence interval [CI] 1.08-3.28; HR 2.30, 95\% CI 1.35-3.94). Furthermore, with the classification of the high risk of lymph node metastasis ("positive lymphatic or/and venous invasion" or "submucosal deep (SM2) invasion"), the 5-year survival rate was only $52 \%$ in patients who had non-curative ER without salvage gastrectomy which was significantly lower than the rate of $96 \%$ in patients who had non-curative with salvage gastrectomy. Hence salvage gastrectomy after non-curative ER should be performed for elderly patients who can tolerate the surgical procedure.

\section{Metachronous Gastric Cancer after Endoscopic Resection}

The benefits of ER with preservation of the organs of origin for the carcinoma of stomach will certainly lead to higher risk of development for metachronous gastric cancers. ${ }^{3}$ Indeed there is a higher incidence of metachronous gastric cancer after ER (2.9\%-14.0\%) compared with gastrectomy (1.8\%-2.4\%). The Japanese Society for Helicobacter Research recommends Helicobacter pylori eradication after endoscopic treatment for EGC to prevent metachronous gastric cancer. ${ }^{26}$ Fukase et $\mathrm{al}^{27}$ demonstrated the incidence of metachronous gastric cancer had significantly reduced after $H$. pylori eradication at a 3-year follow up period (HR 0.339, $95 \%$ CI 0.157-0.729). A recent Korean study also showed the reduction of occurrence of metachronous gastric cancer after $H$. pylori eradication, but this trend did not reach statistical significance (odds ratio 0.36, 95\% CI 0.08-1.70). Upon subgroup analysis of patients who were followed-up for more than 18 months, meta- chronous cancer was significantly reduced in eradication group. ${ }^{28}$

However, the study reported by Maehata et $\mathrm{al}^{29}$ found that eradication of $H$. pylori did not significantly reduce the incidence of metachronous gastric cancer at a follow-up period of 11 years. The baseline severe mucosal atrophy and a follow-up for more than 5 years were independent risk factors for the development of metachronous gastric cancer. Moreover, in a multi-center retrospective cohort study, 65 of 1,258 patients were detected metachronous multiple cancer during a mean follow-up of 26.8 months. The cumulative incidence of metachronous cancers increased linearly and mean annual incidence rate was 3.5\%. But eradication of $H$. pylori did not reduce the incidence of metachronous cancers. ${ }^{30}$

Overall, the risk of metachronous gastric cancer seems to be decreased after $H$. pylori eradication, but the results were not consistent among reported studies. ${ }^{31}$ In clinical relevance, it is important to identify the particular patients with the high risk of metachronous gastric cancer after ER, who should be given the close monitor and follow-up surveillance. Providing metachronous gastric cancer may be developed long after $H$. pylori eradication, long term surveillance endoscopy should be recommended. Meanwhile, $H$. pylori eradication had better been performed before the progression of gastric mucosal atrophy so that the metachronous gastric cancer can be prevented effectively. ${ }^{31}$

\section{Conclusion}

ER is the current standard of treatment for intramucosal EGC. Recent studies demonstrated the effectiveness of ESD to achieve oncological clearance for EGC in the category of expanded criteria with favorable long term. One of the main concerns is the differentiation of patients with high risk of lymph node metastasis under expanded criteria for ER and further research is warranted to delineate risk and to identify predictors of nodal metastasis. For the increasing elderly population with concomitant diseases and higher risks of surgical complications, ESD will serve as excellent curative treatment for EGCs. After ESD, regular surveillance endoscopy should be performed to detect metachronous cancer. $H$. pylori eradication appeared to reduce the risk of metachronous cancer, and the combination of other risk factors such as extent of mucosal atrophy and the type of differentiation is still lacking to further stratify those with high risk of developing metachronous cancer.

\section{Conflicts of Interest}

No potential conflict of interest relevant to this article was reported.

\section{References}

1. Kim YI, Kim YW, Choi IJ, Kim CG, Lee JY, Cho SJ, et al. Long-term survival after endoscopic resection versus surgery in early gastric cancers. Endoscopy. 2015;47:293-301.

2. Choi IJ, Lee JH, Kim YI, Kim CG, Cho SJ, Lee JY, et al. Long-term outcome comparison of endoscopic resection and surgery in early gastric cancer meeting the absolute indication for endoscopic resection. Gastrointest Endosc. 2015;81:333-41. e331.

3. Park CH, Lee H, Kim DW, Chung H, Park JC, Shin SK, et al. Clinical safety of endoscopic submucosal dissection compared with surgery in elderly patients with early gastric cancer: a propensity-matched analysis. Gastrointest Endosc. 2014;80:599-609.

4. Kim DY, Hong SJ, Cho GS, Jeong GA, Kim HK, Han JP, et al. Long-term efficacy of endoscopic submucosal dissection compared with surgery for early gastric cancer: a retrospective cohort study. Gut Liver. 2014;8:519-25.

5. Chiu PW, Teoh AY, To KF, Wong SK, Liu SY, Lam CC, et al. Endoscopic submucosal dissection (ESD) compared with gastrectomy for treatment of early gastric 
neoplasia: a retrospective cohort study. Surg Endosc. 2012;26:3584-91.

6. Chiu PW, Lai PB. Endoscopic resection for early gastric cancer: what is the limit? Ann Surg Oncol. 2015;22:1753-4.

7. Japanese Gastric Cancer Association. Japanese gastric cancer treatment guidelines 2010 (ver. 3). Gastric Cancer. 2011;14:113-23.

8. Gotoda T. Endoscopic resection of early gastric cancer. Gastric Cancer. 2007;10:111.

9. Gotoda T, Yanagisawa A, Sasako M, Ono H, Nakanishi Y, Shimoda T, et al. Incidence of lymph node metastasis from early gastric cancer: estimation with a large number of cases at two large centers. Gastric Cancer. 2000;3:219-25.

10. Choi J, Kim SG, Im JP, Kim JS, Jung HC. Long-term clinical outcomes of endoscopic resection for early gastric cancer. Surg Endosc. 2015;29:1223-30.

11. Nakamura K, Honda K, Akahoshi K, Ihara E, Matsuzaka H, Sumida Y, et al. Suitability of the expanded indication criteria for the treatment of early gastric cancer by endoscopic submucosal dissection: Japanese multicenter large-scale retrospective analysis of short- and long-term outcomes. Scand J Gastroenterol. 2015;50:413-22.

12. Kang MS, Hong SJ, Kim DY, Han JP, Choi MH, Kim HK, et al. Long-term outcome after endoscopic submucosal dissection for early gastric cancer: focusing on a group beyond the expanded indication. J Dig Dis. 2015;16:7-13.

13. Shin KY, Jeon SW, Cho KB, Park KS, Kim ES, Park CK, et al. Clinical outcomes of the endoscopic submucosal dissection of early gastric cancer are comparable between absolute and new expanded criteria. Gut Liver. 2015;9:181-7.

14. Ohnita $\mathrm{K}$, Isomoto $\mathrm{H}$, Shikuwa $\mathrm{S}$, Yajima $\mathrm{H}$, Minami $\mathrm{H}$, Matsushima $\mathrm{K}$, et al. Early and long-term outcomes of endoscopic submucosal dissection for early gastric cancer in a large patient series. Exp Ther Med. 2014;7:594-8.

15. Oda I, Oyama T, Abe S, Ohnita K, Kosaka T, Hirasawa K, et al. Preliminary results of multicenter questionnaire study on long-term outcomes of curative endoscopic submucosal dissection for early gastric cancer. Dig Endosc. 2014;26:214-9.

16. Kosaka T, Endo M, Toya Y, Abiko Y, Kudara N, Inomata M, et al. Long-term outcomes of endoscopic submucosal dissection for early gastric cancer: a singlecenter retrospective study. Dig Endosc. 2014;26:183-91.

17. Park CH, Shin S, Park JC, Shin SK, Lee SK, Lee YC, et al. Long-term outcome of early gastric cancer after endoscopic submucosal dissection: expanded indication is comparable to absolute indication. Dig Liver Dis. 2013;45:651-6.

18. Lee H, Yun WK, Min BH, Lee JH, Rhee PL, Kim KM, et al. A feasibility study on the expanded indication for endoscopic submucosal dissection of early gastric cancer. Surg Endosc. 2011;25:1985-93.

19. Ahn JY, Jung HY, Choi KD, Choi JY, Kim MY, Lee JH, et al. Endoscopic and oncologic outcomes after endoscopic resection for early gastric cancer: 1370 cases of absolute and extended indications. Gastrointest Endosc. 2011;74:485-93.
20. Jee YS, Hwang SH, Rao J, Park DJ, Kim HH, Lee HJ, et al. Safety of extended endoscopic mucosal resection and endoscopic submucosal dissection following the Japanese Gastric Cancer Association treatment guidelines. Br J Surg. 2009;96: 1157-61.

21. Abe S, Oda I, Suzuki H, Nonaka S, Yoshinaga S, Odagaki T, et al. Short- and longterm outcomes of endoscopic submucosal dissection for undifferentiated early gastric cancer. Endoscopy. 2013;45:703-7.

22. Okada K, Fujisaki J, Yoshida T, Ishikawa H, Suganuma T, Kasuga A, et al. Longterm outcomes of endoscopic submucosal dissection for undifferentiated-type early gastric cancer. Endoscopy. 2012;44:122-7.

23. Oka S, Tanaka S, Higashiyama M, Numata N, Sanomura Y, Yoshida S, et al. Clinical validity of the expanded criteria for endoscopic resection of undifferentiatedtype early gastric cancer based on long-term outcomes. Surg Endosc. 2014;28: 639-47.

24. Tokioka S, Umegaki E, Murano M, Takeuchi N, Takeuchi T, Kawakami K, et al. Utility and problems of endoscopic submucosal dissection for early gastric cancer in elderly patients. J Gastroenterol Hepatol. 2012;27(Suppl 3):63-9.

25. Kusano C, Iwasaki M, Kaltenbach T, Conlin A, Oda I, Gotoda T. Should elderly patients undergo additional surgery after non-curative endoscopic resection for early gastric cancer? Long-term comparative outcomes. Am J Gastroenterol. 2011;106: 1064-9.

26. Asaka M, Kato M, Takahashi S, Fukuda Y, Sugiyama T, Ota H, et al; Japanese Society for Helicobacter Research. Guidelines for the management of Helicobacter pylori infection in Japan: 2009 revised edition. Helicobacter. 2010;15:1-20.

27. Fukase $K$, Kato M, Kikuchi S, Inoue K, Uemura N, Okamoto S, et al; Japan Gas Study Group. Effect of eradication of Helicobacter pylori on incidence of metachronous gastric carcinoma after endoscopic resection of early gastric cancer: an open-label, randomised controlled trial. Lancet. 2008;372:392-7.

28. Seo JY, Lee DH, Cho Y, Lee DH, Oh HS, Jo HJ, et al. Eradication of Helicobacter pylori reduces metachronous gastric cancer after endoscopic resection of early gastric cancer. Hepatogastroenterology. 2013;60:776-80.

29. Maehata Y, Nakamura S, Fujisawa K, Esaki M, Moriyama T, Asano K, et al. Longterm effect of Helicobacter pylori eradication on the development of metachronous gastric cancer after endoscopic resection of early gastric cancer. Gastrointest Endosc. 2012;75:39-46.

30. Kato M, Nishida T, Yamamoto K, Hayashi S, Kitamura S, Yabuta T, et al. Scheduled endoscopic surveillance controls secondary cancer after curative endoscopic resection for early gastric cancer: a multicentre retrospective cohort study by Osaka University ESD study group. Gut. 2013;62:1425-32.

31. Shiotani A, Haruma K, Graham DY. Metachronous gastric cancer after successful Helicobacter pylori eradication. World J Gastroenterol. 2014;20:11552-9. 